\title{
THE BUREAU OF ALCOHOL, TOBACCO AND FIREARMS (ATF) FIRE RESEARCH LABORATORY
}

\author{
Kenneth D. Steckler \\ Bureau of Alcohol, Tobacco and Firearms \\ Ammendale, MD 20705-1250
}

\begin{abstract}
The U.S. Bureau of Alcohol, Tobacco and Firearms (ATF), Department of the Treasury, is responsible for enforcement of the federal laws on arson, an insidious crime that claims the lives of hundreds of Americans annually and costs billions of dollars. Fire research is crucial to the understanding of fire ignition, growth and spread in real-world situations, and the recognition of post-fire indicators of these phenomena. This information is critical for accurate fire scene analysis and reconstruction that are necessary for effective criminal prosecutions.
\end{abstract}

At the present time there are no fire research facilities in the United States dedicated to the specific needs of the fire investigation community. The new ATF Fire Research Laboratory (FRL) will provide the necessary facilities, equipment, and staff to work on important fire investigation issues, such as fire scene reconstruction (both physical and mathematical-modeling), assessment of fire pattern analysis indicators, impact of accelerants on fire growth, and ignition sources including electrical devices. In addition, FRL staff will provide case support and training for ATF's Certified Fire Investigators (CFIs), prosecutors, and the fire investigation community at-large, and establish a central repository of fire investigation test and research data.

In 2003, the FRL will join two existing laboratories in ATF's new $16,400 \mathrm{~m}^{2}$ National Laboratory Center (NLC) complex on a 35-acre site in Ammendale, Maryland (Fig. 1).

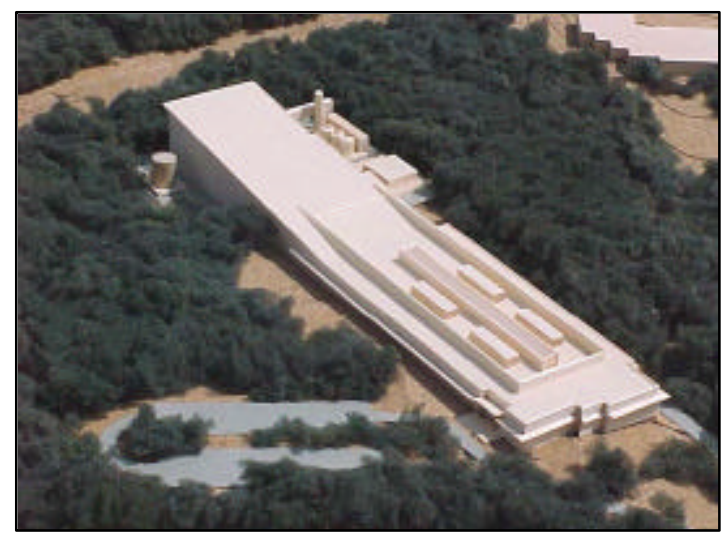

Fig. 1. ATF National Laboratory Center. The FRL will occupy the upper-left onethird of the building complex shown above. 
The NLC will house the ATF Alcohol and Tobacco Laboratory (ATL), the Forensic Science Laboratory Washington (FSL-W), and the FRL. The FRL will occupy approximately $4,600 \mathrm{~m}^{2}$ of the new facility and will contain three burn rooms, electrical laboratory, conditioning rooms, instrumentation rooms, video control/editing room, fire modeling (computer) laboratory, classroom, mechanical shop, construction/test materials storage, evidence storage area, and administrative office space.

The Small Burn Room (SBR) will house standard fire test apparatuses including a Cone Calorimeter, Flooring Radiant Panel, LIFT, and Smoke Chamber. The Medium Burn Room (MBR), with dimensions $45.8 \mathrm{~m}$ x $24.3 \mathrm{~m}$ x $10.2 \mathrm{~m}$ (high), will contain two $1 \mathrm{MW}$ oxygen-consumption calorimeters, a $4 \mathrm{MW}$ calorimeter, two $0.5 \mathrm{MW}$ non-instrumented Niche Hoods (each with a $6 \mathrm{~m} \mathrm{x} 3 \mathrm{~m}$ "footprint"), and an Intermediate-Scale Calorimeter (ICAL). The Large Burn Room, with dimensions 39.0 m x 36.4 m x 15.6 m (high), will contain a $14 \mathrm{MW}$ calorimeter having a $18.5 \mathrm{~m}$ square hood with sufficient clearance to accommodate a two-story test structure.

Four $298 \mathrm{~kW}$ fans will exhaust a total of $85 \mathrm{~m} / \mathrm{s}$ from the two larger burn rooms. Virtually all of this flow can be pulled through the $14 \mathrm{MW}$ calorimeter or partitioned among several of the smaller hoods and ceiling vents. The latter will be located near the four corners of both the MBR and LBR to remove combustion products that are not captured by the calorimeter hoods.

Airflow to the two larger burn rooms will be through an assembly of controllable louvered dampers that contain perforated plates. This design will admit flow at a speed of about $0.6 \mathrm{~m} / \mathrm{s}$ and a pressure drop of about $0.16 \mathrm{~mm} \mathrm{Hg}$ over the full range of ventilation conditions. For a given exhaust flow rate, the number of open dampers will be adjusted to maintain these burn rooms at a negative pressure relative to the adjacent rooms and the outdoors. Under these conditions, all combustion products will be captured by the exhaust system and passed through a state-of-the-art, high efficiency, wet electrostatic precipitator (WESP) for cleaning prior to being released to the outdoors.

A water treatment facility will be built to collect and recycle at least 75 percent of the water used for fire-test suppression. This facility will greatly reduce the impact of FRL operations on municipal water and sewage systems.

To support the investigation of electrical equipment fires, an electrical laboratory with a dedicated 460 VAC, 3 phase, 1000 ampere service will be included in the FRL for testing and failure analyses of residential and commercial electrical equipment and wiring.

KEYWORDS: calorimeters, electrical equipment fires, fire investigations, fire research organizations 